\title{
High-dose sitagliptin for systemic inhibition of dipeptidylpeptidase-4 to enhance engraftment of single cord umbilical cord blood transplantation
}

\author{
Sherif S. Farag ${ }^{1,4}$, Robert Nelson ${ }^{1,4}$, Mitchell S. Cairo ${ }^{5}$, Heather A. O'Leary ${ }^{1,4}$, \\ Shuhong Zhang ${ }^{1}$, Carol Huntley ${ }^{4}$, David Delgado ${ }^{3}$, Jennifer Schwartz ${ }^{1}$, Mohammad \\ Abu Zaid ${ }^{1}$, Rafat Abonour ${ }^{1}$, Michael Robertson ${ }^{1,4}$ and Hal Broxmeyer ${ }^{2,4}$ \\ ${ }^{1}$ Division of Hematology and Oncology, Department of Medicine, Indianapolis, Indiana, USA \\ ${ }^{2}$ Department of Microbiology and Immunology, Indianapolis, Indiana, USA \\ ${ }^{3}$ Department of Pediatrics, Indiana University School of Medicine, Indianapolis, Indiana, USA \\ ${ }^{4}$ Indiana University Simon Cancer Center, Indianapolis, Indiana, USA \\ ${ }^{5}$ Children and Adolescent Cancer and Blood Diseases Center and Department of Pediatrics, New York Medical College, \\ Valhalla, New York, USA \\ Correspondence to: Sherif S. Farag, email: ssfarag@iupui.edu \\ Keywords: cord blood; DPP-4; CD26; engraftment; leukemia \\ Received: October 03, $2017 \quad$ Accepted: October 30, $2017 \quad$ Published: November 27, 2017 \\ Copyright: Farag et al. This is an open-access article distributed under the terms of the Creative Commons Attribution License 3.0 \\ (CC BY 3.0), which permits unrestricted use, distribution, and reproduction in any medium, provided the original author and source \\ are credited.
}

\section{ABSTRACT}

Delayed engraftment remains a limitation of umbilical cord blood (UCB) transplantation. We previously showed that inhibition of dipeptidylpeptidase (DPP)4 using sitagliptin $600 \mathrm{mg}$ daily was safe with encouraging results on engraftment, but inhibition was not sustained. We evaluated the efficacy and feasibility of higher doses of sitagliptin to enhance engraftment of UCB in patients with hematological cancers. Fifteen patients, median age 41 (range, 18-59) years, received single UCB grafts matched at $4(n=11)$ or $5(n=4)$ of 6 HLA loci with median nucleated cell dose of 3.5 (range, $2.57-4.57$ ) $\times 10^{7} / \mathrm{kg}$. Sitagliptin $600 \mathrm{mg}$ every 12 hours was administered days -1 to +2 . All patients engrafted by day 30, with $12(80 \%)$ engrafting by day 21 . The median time to neutrophil engraftment was 19 (range, 12-30) days. Plasma DPP-4 activity was better inhibited with a mean residual trough DPP-4 activity of $70 \% \pm 19 \%$. Compared to patients previously treated with $600 \mathrm{mg} /$ day, sitagliptin $600 \mathrm{mg}$ every 12 hours appeared to improve engraftment, supporting the hypothesis that more sustained DPP-4 inhibition is required. In-vivo inhibition of DPP-4 using high-dose sitagliptin compares favorably with other approaches to enhance UCB engraftment with greater simplicity, and may show synergy in combination with other strategies.

\section{INTRODUCTION}

Umbilical cord blood (UCB) is a source of hematopoietic stem and progenitor cells (HSPC) for transplantation of patients who do not have a human leukocyte antigen (HLA)-matched sibling or adult unrelated donor. However, delayed neutrophil engraftment remains one significant disadvantage of
UCB transplantation [1,2]. Several approaches are being considered to enhance engraftment of UCB, including intraosseous infusion, ex-vivo expansion of hematopoietic progenitors, co-transplantation with accessory cells, and enhancing homing of HSPC to the bone marrow $[1,3]$.

The stromal derived factor (SDF)- $1 \alpha$ :CXCR4 axis plays an important role in homing of stem cells [4], and is modulated by the enzyme dipeptidylpeptidase (DPP)- 
4/CD26 [5]. DPP-4 cleaves the N-terminus dipeptide of $\mathrm{SDF}-1 \alpha$, resulting in a truncated-form of SDF-1 that is unable to activate CXCR4; inhibition of DPP-4 enhances migration of CD34+ cells [5]. In pre-clinical models, DPP-4/CD26 inhibition by ex-vivo pretreatment of donor HSPC or systemic inhibition using specific inhibitors enhanced engraftment of UCB and murine bone marrow cells [6-8]. Recently, we reported the safety of systemic DPP-4 inhibition using the clinical inhibitor sitagliptin, approved for treatment of type 2 diabetes mellitus, to enhance engraftment of single-unit UCB transplantation [9]. Although times to neutrophil engraftment were encouraging, pharmacodynamic studies suggested the schedule of sitagliptin (600 mg daily) was suboptimal in producing sustained inhibition of plasma DPP-4, which correlated with engraftment $[9,10]$. Herein, we present results of a prospective trial of 12-hourly dosing of sitagliptin to enhance neutrophil engraftment of single-unit UCB transplants in patients with high-risk hematological malignancies.

\section{RESULTS}

\section{Patients and graft characteristics}

Fifteen patients were enrolled at Indiana University $(n=14)$ and the New York Medical College $(n=1)$ between January 2013 and July 2016. One patient subsequently found not to have met eligibility because she commenced treatment one day earlier than the prescribed 35-day interval from previous therapy is included in the analysis. The trial was stopped early because of poor accrual. Patients and graft characteristics are summarized in Table 1. All patients received red blood cell-depleted single unit UCB grafts. Notably, 11 of the 15 patients received $4 / 6$ HLA matched UCB units. The median nucleated cell (NC) dose pre-freezing was 3.50 (range, $2.57-4.57$ ) x107/ kg, and the median viable NC dose infused was 2.58 (1.28-3.69) $\mathrm{x} 10^{7} / \mathrm{kg}$. Patient characteristics and cell doses infused were similar to those included in our pilot study [9].

\section{Engraftment outcome}

All 15 patients engrafted by day +30 days following transplantation, with 12 patients engrafting by day +21 . The median time to neutrophil engraftment was 19 (range, 12-30) days, with a median 100\% (range, 95\% - 100\%) donor chimerism at engraftment. Figure $1 \mathrm{~A}$ shows times to neutrophil engraftment of patients treated with sitagliptin $600 \mathrm{mg}$ every 12 hours on the current study compared with the 17 patients also receiving red blood cell-depleted cord blood units but treated with $600 \mathrm{mg}$ daily on our previous trial where the median time to engraftment was 21 (range, 13-50) days $(P=0.060)$ [9]. The cumulative incidence of platelet recovery to $>20 \times 10^{9} / 1$ was $46.7 \%$ (95\% confidence interval [CI], 19.3\% - 74.0\%) by day
+100 , with non-relapse mortality and death from disease relapse as competing risks $(40.0 \%$ [95\% CI, 13.3\% $66.7 \%]$ ). All engraftment was durable in all patients with no secondary graft failures. As an additional comparison, we compared the engraftment of patients treated with sitagliptin $600 \mathrm{mg}$ every 12 hours on the current study with our institutional cohort of 24 consecutive patients who received UCB transplants for hematological malignancies and a variety of non-malignant disorders (other than hemoglobinopathies) without sitagliptin between January 2011 and December 2016 (Figure 1B). The median age of the latter control patients was 4 (range, 0.4-21) years with 13 males and 11 females, who received UCB grafts that were $4 / 6(n=10), 5 / 6(n=8)$, and $6 / 8(n=6)$ HLA-matched and containing a median viable NC dose of $7.2(3.0-43.9) \times 10^{7} / \mathrm{kg}$. As shown, despite more than a two and half fold higher median NC dose, engraftment was significantly slower $(P=0.011)$ with a median time to engraftment of 21.5 (range, days and a cumulative incidence of engraftment of $87 \%$ (95\% CI, 72\% - 100\%) by 100 days post-transplantation.

\section{Toxicity}

Grades 3-4 toxicities were expected and similar to those previously observed [9]. These included mucositis $(\mathrm{n}=5)$, self-limiting sinusoidal obstruction syndrome $(n=1)$, thrombotic microangiopathy $(n=1)$, and multiorgan failure due to sepsis $(n=2)$. Blood glucose levels remained essentially unchanged during the sitagliptin dosing period and no episodes of hypoglycemia were observed (data not shown). Indeed, there were no toxicities that could be specifically related to sitagliptin, confirming the safety of the drug even at much higher doses than those used for diabetes mellitus.

The cumulative incidence of non-relapse mortality at 6 months was $46.7 \%$ (95\% CI 19.9\%-73.5\%), with death due to relapse/progression of disease a competing risk. Infections, including concurrent adenovirus hepatitis and human herpes virus-6 ( $\mathrm{n}=1)$, Escherichia coli meningitis $(n=1)$, vancomycin-resistant enterococcus sepsis $(n=2)$, hospital-acquired pneumonia $(\mathrm{n}=1)$, and aspergillus infection $(n=1)$ were causes of death in 7 patients within the first 180 days, with an additional patient dying on day +217 from Stenotrophomonas maltophila sepsis. Non-fatal cytomegalovirus viremia and herpes simplex stomatitis occurred in 4 and 2 patients, respectively. Only one patient developed acute GvHD of the skin, clinical grade 1, during tapering of immunosuppression drugs, which promptly resolved with topical corticosteroid treatment.

\section{Plasma DDP-4 activity}

The plasma DPP-4 activity was measured at baseline and after dosing, and levels were expressed as residual activity as a percentage of baseline (Figure 2). Maximal 
All Patients

$(\mathrm{N}=15)$

Age, median (range) years

Weight, median (range) $\mathrm{kg}$

$\mathrm{M} / \mathrm{F}, \mathrm{n}$

Diagnosis, $\mathrm{n}$

AML

CR1

CR3

Primary refractory

ALL

CR1

Primary refractory

MDS, therapy-related

DLBCL, Relapsed and refractory

Number of prior chemotherapy cycles, median (range)

Days from diagnosis to transplant, median (range)

HLA-match, $n$

5 of 6

4 of 6

UCB graft characteristics:

Pre-freeze NC, median (range) $\left(\times 10^{7} / \mathrm{kg}\right)$

Post-thaw viable NC, median (range) $\left(\mathrm{x} 10^{7} / \mathrm{kg}\right)$

Post-thaw viable cell recovery, median (range) (\%)

Post-thaw CD34+ cells, median (range) $\left(\times 10^{5} / \mathrm{kg}\right)$

CFU, median (range) $\left(\mathrm{x} 10^{4} / \mathrm{kg}\right)$
$41(18-59)$

$82.1(51.4-133.5)$

$6 / 9$
7

1

2

2

1

1

1

$3(1-10)$

156 (87-1234)

4

11

$3.50(2.57-4.57)$

2.58 (1.28-3.69)

72 (47-80)

2.5 (1.0-7.0)

$2.3(1.2-7.0)$

Abbreviations: AML, acute myeloid leukemia; ALL, acute lymphoblastic leukemia; DLBCL, diffuse large B-cell lymphoma; MDS, myelodysplastic syndrome; CR, complete remission; NC, nucleated cell count; CFU, colony forming units.

inhibition of plasma DPP-4 activity occurred at 2-4 hours after dosing. The mean ( \pm standard error) plasma DPP-4 activity at 4 hours after dosing was $56 \% \pm 16 \%$ of baseline. Inhibition of plasma DPP-4 was better sustained through the dosing interval, with mean residual trough DPP-4 activity of $70 \% \pm 19 \%$. The median area under the total percent residual DPP-4 activity versus time curve ( $\left.\mathrm{AUC}_{\mathrm{A}}\right)$ for the dosing period was 3,130 (range, 2,004-4,636) $\mathrm{h}^{*}$ activity, which was significantly lower than that seen in our previous trial using $600 \mathrm{mg}$ sitagliptin daily (median 5,169 [range, 2,932-7,530] h*activity; $P=0.000013$ ) [9]. There was no correlation between maximal inhibition of plasma DPP-4, mean trough levels of DPP-4 activity, or $\mathrm{AUC}_{\mathrm{A}}$ and engraftment in the current trial (result not shown).

\section{DISCUSSION}

Cell dose is an important determinant of engraftment and long-term outcomes following UCB transplantation $[11,12]$. This has led to use of double-unit UCB grafts such that double-unit UCB transplants have exceeded those using single UCB units in recent years [13], without definitive proof of benefit. A recent randomized trial comparing single- versus double-unit UCB transplants did not shown enhanced engraftment or improvement in 
A

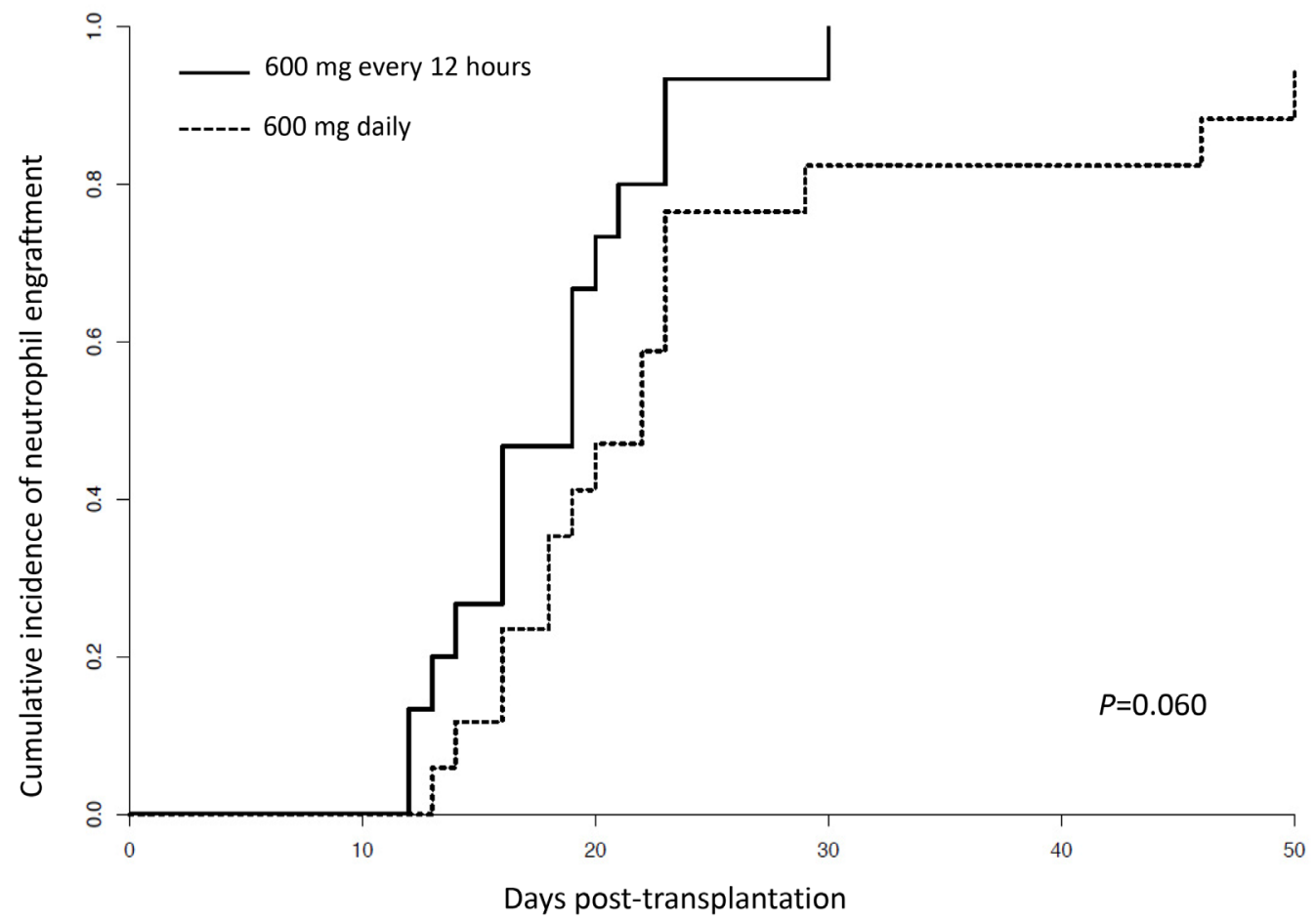

B

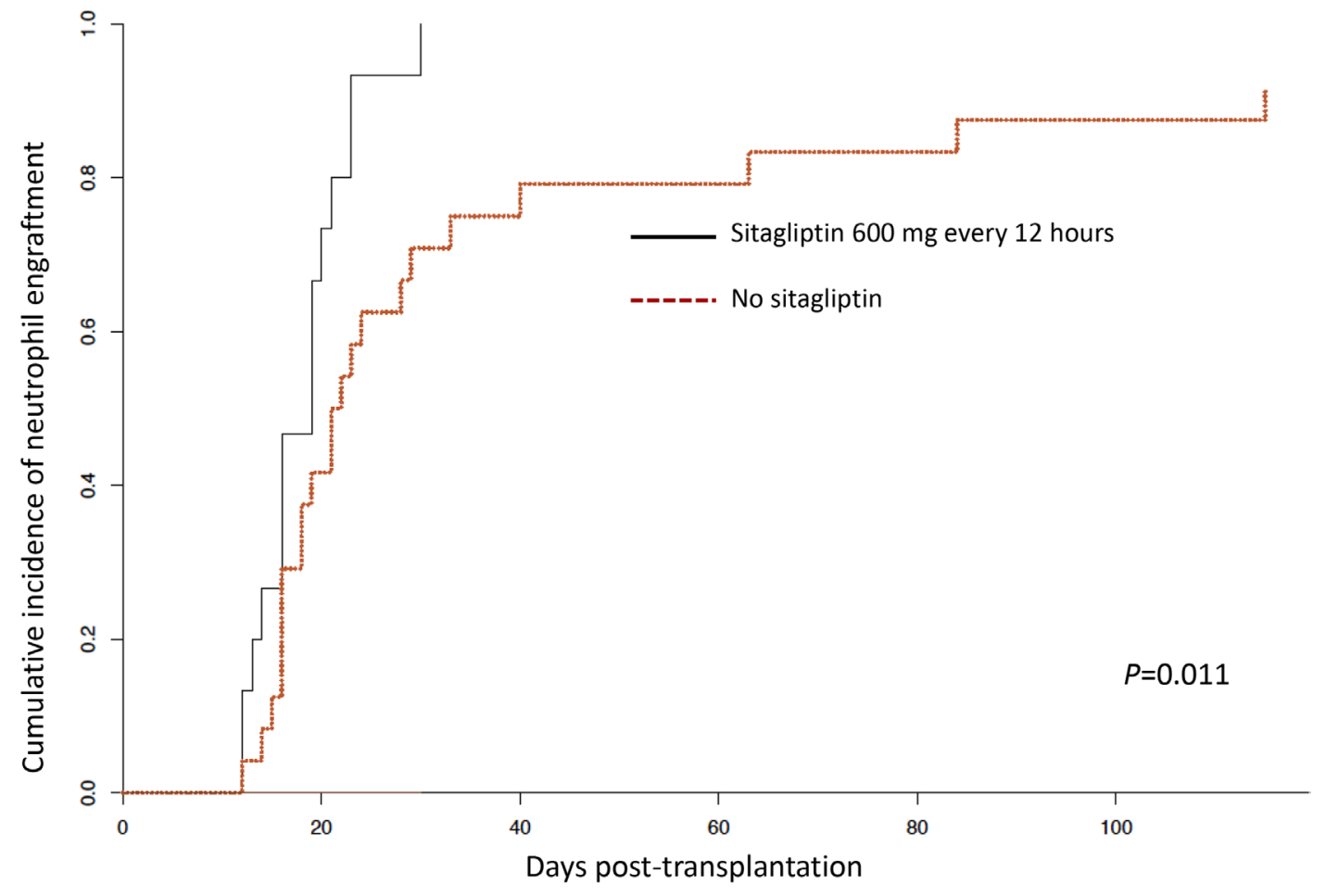

Figure 1: Neutrophil engraftment. (A) Cumulative incidence of neutrophil engraftment comparing patients receiving sitagliptin 600 mg every 12 hours $(\mathrm{n}=15)$ in the current trial with also those receiving $600 \mathrm{mg}$ sitagliptin once daily and red blood cell-depleted UCB units, previously reported $(\mathrm{n}=17){ }^{9}$ (B) Cumulative incidence of neutrophil engraftment comparing patients receiving sitagliptin $600 \mathrm{mg}$ every 12 hours $(\mathrm{n}=15)$ in the current trial with an institutional control of 24 patients receiving UCB transplants without sitagliptin during a similar time interval (see text for detail). 
treatment-related mortality, relapse, or overall survival following double-unit UCB transplants [14]; the authors concluding that single-unit UCB transplants remain a standard of care. We focused on enhancing engraftment of single-unit UCB transplants, as we felt this was the best way to definitively investigate the potential efficacy of DPP-4 inhibition.

The observed kinetics of engraftment in this trial compare quite favorably with other reports where comparable doses and degree of human leukocyte antigen (HLA)-mismatching between UCB unit and recipient were used, as well with other approaches tested to enhance engraftment [15-19], where delays in engraftment still occurs in a proportion of patients and primary graft failure remains problematic. Furthermore, many of the reported approaches to enhance engraftment remain complex, require ex-vivo manipulation, and are costly, presenting economic concerns [20], and may be prohibitive for some centers. In our current trial, all patients engrafted neutrophils within 30 days, and 12 of the $15(80 \%)$ patients engrafted before day 21 . No graft failures were observed. The higher dose (600 mg twice daily) of sitagliptin used in this trial produced more sustained inhibition of plasma DPP-4, with a median $\mathrm{AUC}_{\mathrm{A}}$ of 3,130 (range, 2,004$4,636) h^{*}$ activity, significantly lower than that seen in our previous trial using $600 \mathrm{mg}$ sitagliptin daily (median 5,169 [range, 2,932-7,530] h*activity; $P=0.000013$ ) [9]. This may have accounted for the faster engraftment kinetics observed compared to our previously reported pilot trial where plasma DPP-4 inhibition was not sustained with only $600 \mathrm{mg}$ daily of sitagliptin despite similar TNC (median $3.5 \times 10^{7} / \mathrm{kg}$ vs $3.61 \times 10^{7} / \mathrm{kg}, P=0.28$ ) and similar CD34 (median $2.6 \times 10^{4} / \mathrm{kg}$ vs $1.0 \times 10^{4} / \mathrm{kg}, P=0.27$ ) doses used in patients also receiving red blood cell-depleted UCB units [9], supporting the hypothesis that more sustained DPP-4 inhibition may be required for enhanced engraftment. Unlike in our previously reported study [9], residual $\mathrm{AUC}_{\mathrm{A}}$ did not correlate with engraftment kinetics in the current study. However, we do not believe that this is necessarily contradictory as it is possible that once below a threshold of residual DPP-4 activity is reached by multiple daily dosing of sitagliptin, further improvement in the speed of engraftment may not be observed. Of note, despite more than a two and a half fold lower infused $\mathrm{NC}$ dose, the engraftment kinetics of patients treated on the current study were also significantly faster than an institutional cohort of 24 consecutive patients who received UCB transplants without sitagliptin during the same time interval. As DPP-4 also decreases GM-CSF, G-CSF, interleukin-3 and erythropoietin activities, and inhibition/deletion of DPP-4 enhances their activities and hematopoietic recovery in vivo after cytotoxic stress in preclinical studies [6], longer administration of sitagliptin may further enhance engraftment.

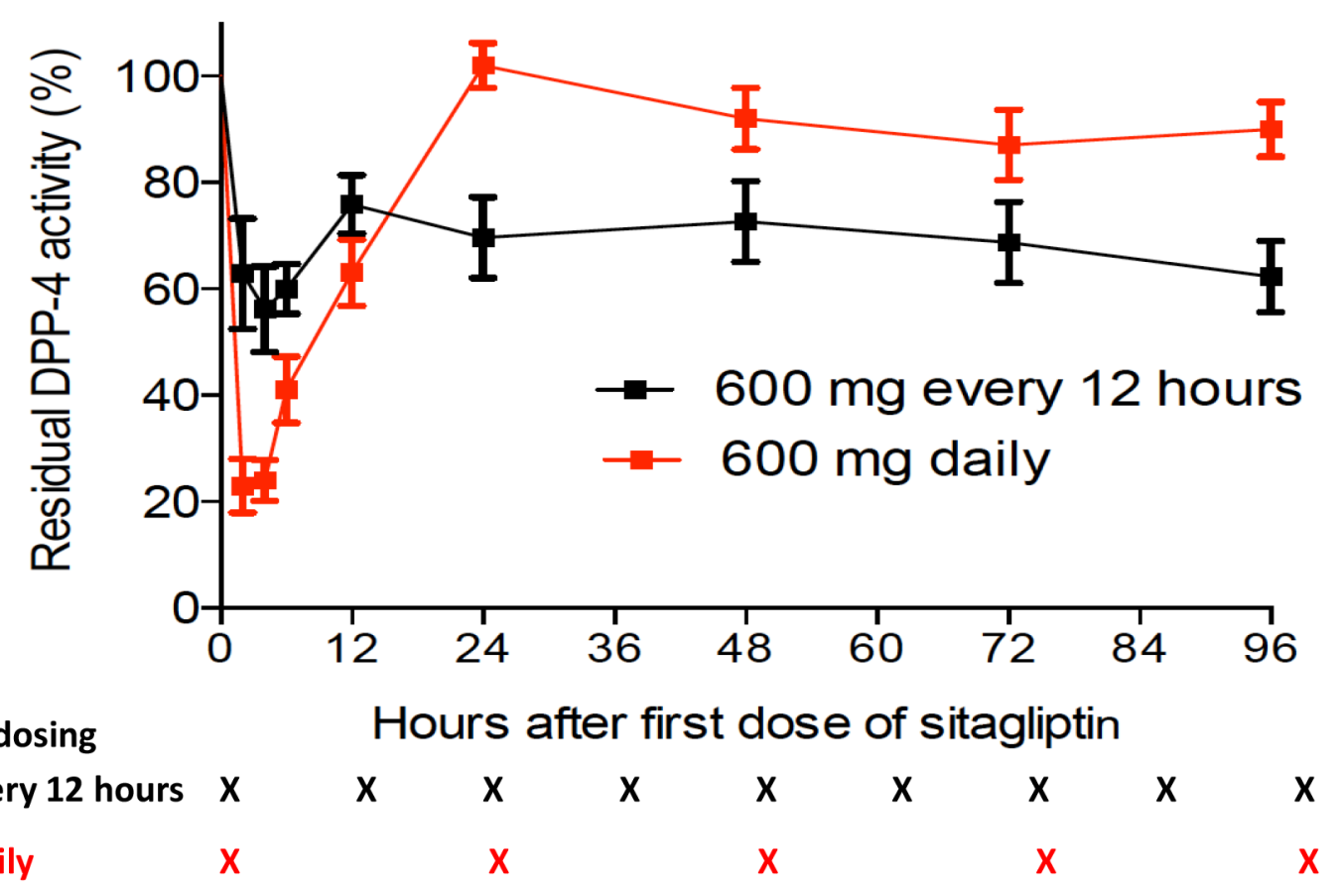

Figure 2: Plasma DPP-4 activity. DPP-4 activity following the first following dose of sitagliptin (started on day -1) shown as percentages of baseline, comparing the residual activity in patients treated with sitagliptin $600 \mathrm{mg}$ every 12 hours on the current study with those receiving sitagliptin $600 \mathrm{mg}$ once daily (black curve) and red blood cell depleted UCB transplants, previously reported (red curve). ${ }^{9}$ Times of sitagliptin administration are indicated by " $\mathrm{X}$ " at the bottom of the figure.

*Indicate trough levels. 
The higher dose of sitagliptin was well tolerated. Overall, grades 3-4 toxicities were expected and similar to previously observed [9]. Specifically, there were no episodes of hypoglycemia or toxicity that could be specifically related to sitagliptin, supporting the safety of the drug when administered at much higher doses than those used for diabetes mellitus. Despite earlier neutrophil recovery, however, infections remained the commonest cause of death. Because of the small number of patients included, it is not possible to determine if sitagliptin increased the risk of infection. However, preliminary observations from an ongoing phase II trial (NCT02683525) testing sitagliptin for prevention of graftversus-host disease following peripheral blood stem cell transplantation from matched related and unrelated donors do not suggest that in-vivo DPP-4 inhibition increases the risk of infections (unpublished). Further, our use of ATG in the current trial may have also contributed to the high incidence of infections observed. Notwithstanding, infections are a recognized problem early following UCB transplantation due to delayed immune recovery [21], and highlight the need to improve immune function beyond neutrophil engraftment.

A limitation of our current study is the small number of patients treated. Indeed, the trial failed to meet its accrual goal, in part reflecting the reluctance of clinicians to use single UCB units in adults despite the lack of proven benefit of double UCB units [14]. Importantly, the primary endpoint (engraftment by day +30 ) satisfied success criteria of the first stage of the trial, and the conditional probability that the null hypothesis would be rejected if the study was continued to full planned accrual is greater than $99 \%$.

Overall, our results indicate that systemic DPP4 inhibition using high-dose sitagliptin given every 12-hourly enhances engraftment of single-unit UCB transplants, and may offer additional benefits over other strategies in terms of simplicity and lower cost. It is also possible that other strategies may be potentially synergistic with in vivo DPP-4 inhibition. In particular, $\mathrm{PGE}_{2}$ treatment of donor cells combined with systemic DPP-4 inhibition may be synergistic [22], and also $\mathrm{PGE}_{2}$ induces and maintains naïve and memory CD8+ T cells [23], which could improve immune dysfunction following UCB transplantation.

\section{MATERIALS AND METHODS}

\section{Study design}

Eligible patients were aged 18-59 years, had acute myeloid (AML) or lymphoblastic leukemia (ALL), highrisk myelodysplasia, or relapsed chemotherapy-refractory aggressive non-Hodgkin's lymphoma, Karnofsky performance status $\geq 70 \%$, adequate organ function, and did not have a readily available HLA-matched sibling or volunteer unrelated donor. Patients with diabetes mellitus requiring insulin or oral hypoglycemic agents, and those with a history of pancreatitis, symptomatic cholelithiasis, or a history hypersensitivity to sitagliptin were excluded. Other eligibility criteria were as previously described [9]. The trial was approved by the institutional review boards of Indiana University and New York Medical College.

\section{Study treatment and selection of UCB graft}

The preparative regimen consisted of high-dose melphalan $\left(140 \mathrm{mg} / \mathrm{m}^{2}\right.$ on day -8$)$, thiotepa $(10 \mathrm{mg} / \mathrm{kg}$ actual body weight on day -7$)$, fludarabine $\left(40 \mathrm{mgm}^{2}\right.$ on days -6 to -3$)$, and rabbit anti-thymocyte globulin $(1.5 \mathrm{mg} /$ $\mathrm{kg}$ on day -3 , and $1.25 \mathrm{mg} / \mathrm{kg}$ on days -2 and -1 ; total dose $4 \mathrm{mg} / \mathrm{kg}$ ) as previously described [24]. Sitagliptin (Januvia $^{\circledR}$; Merck \& Co., Inc., Whitehouse Station, NJ) $600 \mathrm{mg}$ every 12 hours orally was administered on days -1 through +3 ; we previously determined in a dose-escalation study that this dose and schedule produced more sustained plasma DPP-4 inhibition without significant toxicity [25]. Graft-versus-host disease (GvHD) prophylaxis used sirolimus and tacrolimus as previously described [9]. Filgrastim ( $5 \mu \mathrm{g} / \mathrm{kg} /$ day subcutaneously) was started on day +5 and continued until neutrophil recovery. Patients received standard antibiotic prophylaxis using ciprofloxacin, posaconazole and acyclovir against bacterial, mold and viral infections, respectively.

Patients received only single, red blood cell-depleted UCB units that were matched at 4 or more of 6 HLA loci, and contained $>2.5 \times 10^{7} / \mathrm{kg} \mathrm{NC}$ before freezing [9]. UCB units with the best HLA-match were preferred, and within an HLA match level units with greatest NC numbers were selected.

\section{Endpoints, sample size and statistical analysis}

The primary endpoint of the trial was neutrophil engraftment. The trial was designed to demonstrate an increase in the proportion of patients engrafting by day +30 to $\geq 70 \%$ from an expected $50 \%$, based on results in patients transplanted with single unit UCB units of similar cell doses and degree of HLA-mismatch [26]. Standard definitions of times to neutrophil engraftment and platelet recovery were used [9]. Toxicity was graded using the NCI Common Terminology Criteria for Adverse Events v3.0. Cumulative incidences of neutrophil and platelet engraftment were calculated from day 0 until neutrophil engraftment and platelet recovery, respectively, with death prior to recovery a competing risk. Cumulative incidence of non-relapse mortality (NRM) was calculated from day 0 to death from any cause other than relapse, with death due to relapse a competing risk. Pharmacodynamic studies of DPP-4 activity and calculation of the area under the residual DPP-4 activity versus time curve $\left(\mathrm{AUC}_{\mathrm{A}}\right)$ was performed as previously reported [9]. Analyses were 
performed using SPSS version 22 (IBM Corporation, Armonk, NY), and R version 3.3.0 statistical programs.

\section{Abbreviations}

ALL: acute lymphoblastic leukemia; AML: acute myeloid leukemia; AUC: area under the curve; CFU: colony-forming unit; CR: complete remission; DLBCL: diffuse large B cell lymphoma; DPP-4: dipeptidylpeptidase-4; GvHD: graft-versus-host disease; HLA: human leukocyte antigen; HSPC: hematopoietic stem and progenitor cell; MDS: myelodysplastic syndrome; NC: nucleated cell; SDF-1 $\alpha$ : stromal cell derived factor-1 $\alpha$; UCB: umbilical cord blood.

\section{Author contributions}

The following describes the nature of the authors' contributions:

Sherif S. Farag designed and executed the study, analyzed the data and wrote the manuscript.

Robert Nelson assisted in the execution of the study and critically revised the manuscript.

Mitchell Cairo contributed patients to the study and critically revised the manuscript.

Heather O'Leary analyzed the data and critically revised the manuscript.

Shuhong Zhang analyzed the data and critically revised the manuscript.

Carol Huntley assisted in the execution of the study critically revised the manuscript.

Jennifer Schwartz assisted in the execution of the study and critically revised the manuscript.

Mohammad Abu Zaid assisted in the execution of the study and critically revised the manuscript.

Rafat Abonour assisted in the execution of the study and critically revised the manuscript.

Michael Robertson assisted in the execution of the study and critically revised the manuscript.

Hal Broxmeyer assisted in the design of the study, analysis of data, and critically revised the manuscript.

\section{CONFLICTS OF INTEREST}

The authors report no conflicts of interest.

\section{FUNDING}

This work was supported by grants from Public Service multi-PI R01HL112669 from the National Heart Lung and Blood Institute (NHLBI) of the National Institutes of Health (NIH) of the United States (HEB and SSF) and the V Foundation for Cancer Research (SSF).

\section{REFERENCES}

1. Broxmeyer HE. Enhancing the efficacy of engraftment of cord blood for hematopoietic cell transplantation. Transfus Apher Sci. 2016. https://doi.org/10.1016/j. transci.2016.05.013.

2. Ballen KK, Gluckman E, Broxmeyer HE. Umbilical cord blood transplantation: the first 25 years and beyond. Blood. 2013; 122:491-8. https://doi.org/10.1182/ blood-2013-02-453175.

3. Beksac M, Yurdakul P. How to Improve Cord Blood Engraftment? Front Med (Lausanne). 2016; 3:7. https://doi. org/10.3389/fmed.2016.00007.

4. Peled A, Petit I, Kollet O, Magid M, Ponomaryov T, Byk T, Nagler A, Ben-Hur H, Many A, Shultz L, Lider O, Alon R, Zipori D, et al. Dependence of human stem cell engraftment and repopulation of NOD/SCID mice on CXCR4. Science. 1999; 283:845-8.

5. Christopherson KW 2nd, Hangoc G, Broxmeyer HE. Cell surface peptidase CD26/dipeptidylpeptidase IV regulates CXCL12/stromal cell-derived factor-1 alpha-mediated chemotaxis of human cord blood CD34+ progenitor cells. J Immunol. 2002; 169:7000-8.

6. Broxmeyer HE, Hoggatt J, O'Leary HA, Mantel C, Chitteti BR, Cooper S, Messina-Graham S, Hangoc G, Farag S, Rohrabaugh SL, Ou X, Speth J, Pelus LM, et al. Dipeptidylpeptidase 4 negatively regulates colonystimulating factor activity and stress hematopoiesis. Nat Med. 2012; 18:1786-96. https://doi.org/10.1038/nm.2991.

7. Christopherson KW 2nd, Hangoc G, Mantel CR, Broxmeyer HE. Modulation of hematopoietic stem cell homing and engraftment by CD26. Science. 2004; 305:1000-3. https:// doi.org/10.1126/science.1097071.

8. Kawai T, Choi U, Liu PC, Whiting-Theobald NL, Linton GF, Malech HL. Diprotin A infusion into nonobese diabetic/ severe combined immunodeficiency mice markedly enhances engraftment of human mobilized CD34+ peripheral blood cells. Stem Cells Dev. 2007; 16:361-70. https://doi.org/10.1089/scd.2007.9997.

9. Farag SS, Srivastava S, Messina-Graham S, Schwartz J, Robertson MJ, Abonour R, Cornetta K, Wood L, Secrest A, Strother RM, Jones DR, Broxmeyer HE. In Vivo DPP-4 Inhibition to Enhance Engraftment of Single-Unit Cord Blood Transplants in Adults with Hematological Malignancies. Stem Cells Dev. 2013; 22:1007-15. https:// doi.org/10.1089/scd.2012.0636.

10. Velez de Mendizabal N, Strother RM, Farag SS, Broxmeyer HE, Messina-Graham S, Chitnis SD, Bies RR. Modelling the Sitagliptin Effect on Dipeptidyl Peptidase-4 Activity in Adults with Haematological Malignancies After Umbilical Cord Blood Haematopoietic Cell Transplantation. Clin Pharmacokinet. 2014; 53:247-59. https://doi.org/10.1007/ s40262-013-0109-y. 
11. Wagner JE, Barker JN, DeFor TE, Baker KS, Blazar BR, Eide C, Goldman A, Kersey J, Krivit W, MacMillan ML, Orchard PJ, Peters C, Weisdorf DJ, et al. Transplantation of unrelated donor umbilical cord blood in 102 patients with malignant and nonmalignant diseases: influence of CD34 cell dose and HLA disparity on treatment-related mortality and survival. Blood. 2002; 100:1611-8. https:// doi.org/10.1182/blood-2002-01-0294.

12. Gluckman E, Rocha V, Arcese W, Michel G, Sanz G, Chan KW, Takahashi TA, Ortega J, Filipovich A, Locatelli F, Asano S, Fagioli F, Vowels M, et al. Factors associated with outcomes of unrelated cord blood transplant: guidelines for donor choice. Exp Hematol. 2004; 32:397-407. https://doi. org/10.1016/j.exphem.2004.01.002.

13. Ruggeri A. Alternative donors: cord blood for adults. Semin Hematol. 2016; 53:65-73. https://doi.org/10.1053/j. seminhematol.2016.01.006.

14. Michel G, Galambrun C, Sirvent A, Pochon C, Bruno B, Jubert C, Loundou A, Yakoub-Agha I, Milpied N, Lutz P, Marie-Cardine A, Gandemer V, Blaise D, et al. Single versus double-unit cord blood transplantation for children and young adults with acute leukemia or myelodysplastic syndrome. Blood. 2016. https://doi.org/10.1182/ blood-2016-01-694349.

15. Wagner JE Jr, Brunstein CG, Boitano AE, DeFor TE, McKenna D, Sumstad D, Blazar BR, Tolar J, Le C, Jones J, Cooke MP, Bleul CC. Phase I/II Trial of StemRegenin-1 Expanded Umbilical Cord Blood Hematopoietic Stem Cells Supports Testing as a Stand-Alone Graft. Cell Stem Cell. 2016; 18:144-55. https://doi.org/10.1016/j. stem.2015.10.004.

16. Cutler C, Multani P, Robbins D, Kim HT, Le T, Hoggatt J, Pelus LM, Desponts C, Chen YB, Rezner B, Armand P, Koreth J, Glotzbecker B, et al. Prostaglandinmodulated umbilical cord blood hematopoietic stem cell transplantation. Blood. 2013; 122:3074-81. https://doi. org/10.1182/blood-2013-05-503177.

17. de Lima M, McNiece I, Robinson SN, Munsell M, Eapen M, Horowitz M, Alousi A, Saliba R, McMannis JD, Kaur I, Kebriaei P, Parmar S, Popat U, et al. Cord-blood engraftment with ex vivo mesenchymal-cell coculture. N Engl J Med. 2012; 367:2305-15. https://doi.org/10.1056/ NEJMoa1207285.

18. Popat U, Mehta RS, Rezvani K, Fox P, Kondo K, Marin D, McNiece I, Oran B, Hosing C, Olson A, Parmar S, Shah $\mathrm{N}$, Andreeff M, et al. Enforced fucosylation of cord blood hematopoietic cells accelerates neutrophil and platelet engraftment after transplantation. Blood. 2015; 125:288592. https://doi.org/10.1182/blood-2015-01-607366.

19. Delaney C, Heimfeld S, Brashem-Stein C, Voorhies H, Manger RL, Bernstein ID. Notch-mediated expansion of human cord blood progenitor cells capable of rapid myeloid reconstitution. Nat Med. 2010; 16:232-6. https://doi.org/ nm.2080.

20. Broxmeyer HE, Farag S. Background and future considerations for human cord blood hematopoietic cell transplantation, including economic concerns. Stem Cells Dev. 2013; 22 Suppl 1:103-10. https://doi.org/10.1089/ scd.2013.0382.

21. Komanduri KV, St John LS, de Lima M, McMannis J, Rosinski S, McNiece I, Bryan SG, Kaur I, Martin S, Wieder ED, Worth L, Cooper LJ, Petropoulos D, et al. Delayed immune reconstitution after cord blood transplantation is characterized by impaired thymopoiesis and late memory T-cell skewing. Blood. 2007; 110:4543-51. https://oi.org/ blood-2007-05-092130.

22. Broxmeyer HE, Pelus LM. Inhbition of DPP4/CD26 and dmPGE2 treatment enhances engraftment of mouse bone marrow hematopoietic stem cells. Blood Cells Mol Dis. 2014; 53:34-8.

23. Li L, Kim HT, Nellore A, Patsoukis N, Petkova V, McDonough S, Politikos I, Nikiforow S, Soiffer R, Antin JH, Ballen K, Cutler C, Ritz J, et al. Prostaglandin E2 promotes survival of naive UCB T cells via the Wnt/ beta-catenin pathway and alters immune reconstitution after UCBT. Blood Cancer J. 2014; 4:e178. https://doi. org/10.1038/bcj.2013.75.

24. Ciurea SO, Saliba RM, Hamerschlak N, Karduss Aurueta AJ, Bassett R, Fernandez-Vina M, Petropoulos D, Worth LL, Chan KW, Couriel DR, Rondon G, Sharma M, Qazilbash M, et al. Fludarabine, melphalan, thiotepa and anti-thymocyte globulin conditioning for unrelated cord blood transplant. Leuk Lymphoma. 2012; 53:901-6. https:// doi.org/10.3109/10428194.2011.631159.

25. Davis T, Farag SS. (2014). Targeting Homing to Enhance Engraftment following Umbilical Cord Blood Stem Cell Transplantation. In: Ballen K, ed. Umbilical Cord Blood Transplantation and Banking: Springer).

26. Barker JN, Scaradavou A, Stevens CE. Combined effect of total nucleated cell dose and HLA match on transplantation outcome in 1061 cord blood recipients with hematologic malignancies. Blood. 2010; 115:1843-9. https://doi. org/10.1182/blood-2009-07-231068. 